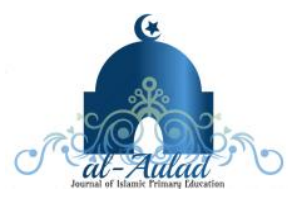

\title{
PENGARUH PENERAPAN STRATEGI INQUIRING MINDS WANT TO KNOW TERHADAP HASIL BELAJAR SISWA
}

\author{
Af'idatun Nisaul Khoiroh ${ }^{1}$, Imas Kania Rahman ${ }^{1}$, Suhendra $^{1}$ \\ ${ }^{1}$ Jurusan Pendidikan Guru Madrasah Ibtidaiyah, Universitas Ibn Khaldun, Bogor, Indonesia \\ adatun005@gmail.com
}

Naskah diterima: tanggal 7 September 2018, direvisi: tanggal 30 September 2018, diterbitkan: tanggal 31 Oktober 2018

\begin{abstract}
This research aims to determine whether there are differences in student learning outcomes that use learning with inquiring minds want to know strategy and students who use conventional learning lectures. The research method used is Quasi Experimental Design with non-equivalent kontrol group design.The research sample is class $3 C$ as many as 25 students as an experimental class and $3 D$ class as many as 25 students as a kontrol class. Data collection techniques using a test, which consist of pretest and posttest questions. Data analysis using Independent Sample tTest with $t$ count obtained in the Independent sample $t$-Test is 2,932. Whereas the t table for the 5\% significance level is 2.02 and $1 \%$ is 2.69 , it can be seen that $t$ count is greater than t table that is $2.02<2.932>2.69$, meaning that there are differences in learning outcomes between experimental and kontrol classes. So it can be said that the Inquiring Minds Want to know Strategy influences student learning outcomes on "Money type and use" material.
\end{abstract}

Keywords: Inquiring Minds Want to Know, learning outcomes

\begin{abstract}
ABSTRAK
Penelitian ini bertujuan untuk mengetahui ada tidaknya perbedaan hasil belajar siswa yang menggunakan pembelajaran dengan strategi inquiring minds want to know dengan siswa yang menggunakan pembelajaran konvensional ceramah. Metode peneliian yang digunakan adalah metode Eksperimen Semu atau Quasi Eksperimental Design dengan rancangan non-equivalent kontrol group design. Sampel penelitian kelas 3C sebanyak 25 siswa sebagai kelas eksperimen dan kelas 3D sebanyak 25 siswa sebagai kelas kontrol. Teknik pengumpulan data menggunakan test, yang terdiri dari soal pretest dan posttest. Analisis data menggunakan uji Independent Sample tTest dengan $\mathrm{t}$ hitung yang didapatkan dalam uji Independent sample t-Test adalah 2.932. Sedangkan t tabel untuk taraf signifikansi $5 \%$ adalah 2.02 dan $1 \%$ adalah 2.69. Sehingga dapat diketahui bahwa $t$ hitung lebih besar daripada t tabel yaitu $2.02<2.932>2.69$, artinya terdapat perbedaan hasil belajar antar kelas eksperimen dan kontrol. Sehingga dapat dikatakan bahwa Strategi Inquiring Minds Want to know berpengaruh terhadap hasil belajar siswa pada materi "Jenis uang dan kegunannya".
\end{abstract}

Kata Kunci: Hasil Belajar, Inquiring Minds Want to Know

\section{PENDAHULUAN}

Pendidikan pada dasarnya merupakan usaha sadar untuk mengembangkan potensi sumber daya manusia peserta didik/siswa dalam rangka mempersiapkan kehidupan yang akan datang dalam berbagai aspek kehidupan. Hal ini tentu tidak dapat dipisahkan dari para penggagas pendidikan nasional yang telah mengolah pendidikan nasional sedemikian rupa sehingga terciptalah pendidikan nasional yang lebih baik dan berkualitas yang berguna bagi kehidupan dunia maupun akhirat. 
Pendidikan yang berkualitas ini tercermin dari tujuan pendidikan nasional yang tercantum pada UU Sisdiknas No. 20 tahun 2003 yang menyatakan bahwa pendidikan nasional bertujuan untuk mengembangkan potensi peserta didik agar menjadi manusia yang beriman dan bertaqwa kepada Tuhan Yang Maha Esa, berakhlaq mulia, sehat, berilmu, cakap, kreatif, mandiri, dan menjadi warga negara yang demokratis, serta bertanggung jawab (Abdul majid, 2014, hlm.1).

Berdasarkan tujuan pendidikan nasional tersebut, pendidikan selayaknya berkorelasi dengan tujuan pendidikan nasional yang berkualitas dan bermutu tinggi. Namun pada kenyataannya, Indonesia dihadapkan dengan berbagai permasalahan yang menyebabkan mutu pendidikan Indonesia masih rendah.

Mutu pendidikan yang rendah di Indonesia disebabkan oleh berbagai faktor. Salah satu faktor yang sangat mempengaruhi adalah proses pembelajaran yang belum efektif seperti kelas yang gaduh, pembelajaraan yang tidak kondusif, dan penyampaian materi yang kurang maksimal yang dapat membuat kegiatan belajar mengajar menjadi tidak optimal. Pembelajaran yang efektif didukung oleh beberapa faktor juga, salah satunya adalah guru yang selalu mengembangkan kemampuan dirinya sebagai pendidik untuk menciptakan iklim kelas yang menyenangkan, menarik, dan cakap dalam pemilihan metode, media dan teknik yang sesuai untuk diterapkan di dalam kelas dengan peserta didik yang heterogen.

Mengajar tidak hanya diukur dari penguasaan konten mata pelajaran semata, akan tetapi yang paling penting adalah metode yang digunakan. Sebaik apapun penguasaan materi, tidak akan tersampaikan dengan baik tanpa metode yang sesuai. Dan sebaik apapun metode yang digunakan tidak akan dapat tersampaikan secara maksimal jika guru tidak dapat mengajar menggunakan metode yang dipilih. Jadi keterampilan guru dalam menerapkan metode yang dipilih sangat diperlukan untuk mencapai tujuan pendidikan yang tidak hanya menuntut penguasaan mata pelajaran, akan tetapi juga perkembangan peserta didik dalam berbagai aspek baik personal maupun interaksi sosial.

Pembelajaran selain menambah wawasan keilmuan, sudah selayaknya dapat membangkitkan berbagai karakter baik peserta didik juga, termasuk kerjasama dengan manusia lain terutama dengan temannya. Karakter kerjasama ini dapat dipupuk melalui pembelajaran IPS yang banyak mengusung tema-tema kehidupan pribadi dan sosial.

Selama ini pembelajaran IPS dinilai hanya membutuhkan banyak hafalan dan teori yang disebabkan oleh pembelajaran monoton menggunakan cara-cara yang konvensional dan tradisional seperti ceramah sehingga kurang bermakna. Pembelajaran seperti ini harus dikurangi dan diganti dengan cara yang bisa membangkitkan keingintahuan peserta didik sehingga pembelajaran tidak pasif agar tercapai prestasi belajar yang maksimal.

Berdasarkan pengamatan yang dilakukan peneliti di SDIT Al-Madinah Cibinong Bogor, pembelajaran IPS di kelas berlangsung dalam suasana yang ramai. Akan tetapi, ketika ditanya peserta didik terkesan masih malu, tidak yakin, dan takut untuk menyatakan atau menjawab pertanyaan yang diajukan oleh guru, sehingga meski ramai, kelas cenderung pasif. Siswa menganggap IPS adalah mata pelajaran yang berisi banyak konten tulisan dan sub-sub materi yang membuat siswa beranggapan bahwa IPS merupakan mata pelajaran yang harus dihafalkan. Ditambah strategi yang diterapkan kurang menarik, sehingga siswa jenuh dan malas untuk mempelajari IPS. Hal ini menyebabkan pencapaian hasil belajar IPS kurang maksimal.

Untuk mengurangi masalah yang ada, upaya yang dapat diterapkan adalah menggunakan strategi pembelajaran aktif. Salah satu pembelajaran aktif sederhana yang dapat diterapkan adalah tipe Inquiring Minds Want to Know yang dapat membangkitkan 
keingintahuan siswa dengan merangsang rasa ingin tahu peserta didik dengan mendorong spekulasi mengenai topik atau persoalan (Melvin L. Silbermen, hlm. 104).

Inquiring Minds Want to Know merupakan salah satu dari strategi pembelajaran aktif sederhana yang mana dalam pelaksanaannya strategi ini terpusat pada bagaimana merangsang rasa ingin tahu siswa dengan menghadirkan topik-topik atau suatu persoalan yang kemudian siswa diajak untuk berpikir kritis dan memberikan kesempatan pada peserta didik untuk mengutarakan dugaan-dugaan mereka. Dengan jawaban peserta didik yang beragam inilah guru memulai pembelajaran dan diharapkan peserta didik dapat terbantu dalam memahami pembelajaran.

\section{METODOLOGI}

Penelitian ini menggunakan metode kuasi eksperimen (Quasi-Experimental design) atau yang biasa disebut dengan eksperimen semu dan menggunakan rancangan Nonequivalent Control Group Design yang menggunakan dua kelompok yang dipilih sesuai (Sugiyono, 2016, hlm. 116). Kelompok pertama sebagai kelas eksperimen diberikan treatment atau perlakuan menggunakan strategi Inquiring Minds Want to Know, sedangkan kelompok kedua sebagai kelas kontrol menggunakan cara belajar konvensional ceramah.

Tabel 1. Desain Penelitian

\begin{tabular}{|l|c|c|c|}
\hline Kelompok & Pretest & Treatment & Posttest \\
\hline Eksperimen & $\mathrm{O} 1$ & $\mathrm{X}$ & $\mathrm{O} 2$ \\
\hline Kontrol & $\mathrm{O} 1$ & & $\mathrm{O} 2$ \\
\hline
\end{tabular}

Keterangan:

O1: Pretest untuk kelas eksperimen dan kontrol.

O2: Posttest untuk kelas eksperimen dan kontrol.

$\mathrm{X}$ : Perlakuan/treatmen.

Dalam penelitian ini, teknik pengumpulan data yang digunakan adalah menggunakan teknik tes. Nana Syaodih Sukmadinata menuturkan bahwa tes hasil belajar atau tes prestasi belajar berfungsi untuk mengukur hasil belajar siswa dalam kurun waktu yang telah ditetapkan (2011, hlm. 223).

Sebelum instrumen digunakan untuk mengambil data dalam penelitian, instrumen harus diuji validitas dan reliabilitasnya terlebih dahulu. Untuk mengetahui valid atau tidaknya suatu instrumen tes, masing-masing pertanyaan dibandingkan. Bila nilai $r$ hitung $>$ $\mathrm{r}$ tabel maka butir soal tersebut dapat dikatakan valid. Nilai $\mathrm{r}$ tabel dicari dengan menggunakan $\mathrm{df}=\mathrm{N}-2=20-2=18$. Sehingga, distribusi tabel signifikan 5\% diperoleh nilai $\mathrm{r}$ tabel sebesar 0,444. Instrumen yang berjumlah 15 soal diujikan kepada 20 responden. Hasil dari uji validitas menyatakan terdapat 14 item soal yang valid dan satu soal yang tidak valid yaitu nomor 2. Sehingga item soal yang akan digunakan dalam mengambil data lapangan adalah sebanyak 14 item soal. Berikut data hasil uji validitas soal 
Tabel 2 Uji Validitas

\section{Correlations}

\begin{tabular}{|c|c|c|}
\hline & & total \\
\hline \multirow{4}{*}{ soal1 } & Pearson Correlation &, $461^{*}$ \\
\hline & Sig. (2-tailed) & 041 \\
\hline & $\mathrm{N}$ & 20 \\
\hline & Pearson Correlation &,- 308 \\
\hline \multirow[t]{3}{*}{ soal2 } & Sig. (2-tailed) & , 186 \\
\hline & $\mathrm{N}$ & 20 \\
\hline & Pearson Correlation &, $589^{* *}$ \\
\hline \multirow[t]{3}{*}{ soal3 } & Sig. (2-tailed) & ,006 \\
\hline & $\mathrm{N}$ & 20 \\
\hline & Pearson Correlation &, $549^{*}$ \\
\hline \multirow[t]{3}{*}{ soal4 } & Sig. (2-tailed) &, 012 \\
\hline & $\mathrm{N}$ & 20 \\
\hline & Pearson Correlation &, $548^{*}$ \\
\hline \multirow[t]{3}{*}{ soal5 } & Sig. (2-tailed) & ,012 \\
\hline & $\mathrm{N}$ & 20 \\
\hline & Pearson Correlation &, $589^{* *}$ \\
\hline \multirow[t]{3}{*}{ soal6 } & Sig. (2-tailed) & ,006 \\
\hline & $\mathrm{N}$ & 20 \\
\hline & Pearson Correlation &, $634^{* *}$ \\
\hline \multirow[t]{3}{*}{ soal7 } & Sig. (2-tailed) & ,003 \\
\hline & $\mathrm{N}$ & 20 \\
\hline & Pearson Correlation &, $671^{* *}$ \\
\hline \multirow[t]{3}{*}{ soal8 } & Sig. (2-tailed) & ,001 \\
\hline & $\mathrm{N}$ & 20 \\
\hline & Pearson Correlation &, $549^{*}$ \\
\hline \multirow[t]{3}{*}{ soal9 } & Sig. (2-tailed) & ,012 \\
\hline & $\mathrm{N}$ & 20 \\
\hline & Pearson Correlation &, $548^{*}$ \\
\hline \multirow[t]{3}{*}{ soal10 } & Sig. (2-tailed) & ,012 \\
\hline & $\mathrm{N}$ & 20 \\
\hline & Pearson Correlation &, $505^{*}$ \\
\hline \multirow[t]{3}{*}{ soal11 } & Sig. (2-tailed) &, 023 \\
\hline & $\mathrm{N}$ & 20 \\
\hline & Pearson Correlation &, $616^{* *}$ \\
\hline \multirow[t]{2}{*}{ soal12 } & Sig. (2-tailed) & ,004 \\
\hline & $\mathrm{N}$ & 20 \\
\hline soal13 & Pearson Correlation &, $616^{* *}$ \\
\hline
\end{tabular}




\begin{tabular}{|ll|r}
\multirow{5}{*}{ soal14 } & Sig. (2-tailed) &, 004 \\
& N & 20 \\
& Pearson Correlation &, $489^{*}$ \\
& Sig. (2-tailed) &, 029 \\
& N & 20 \\
\multirow{5}{*}{ soal15 } & Pearson Correlation &, $549^{*}$ \\
& Sig. (2-tailed) &, 012 \\
& N & 20 \\
& Pearson Correlation & 1 \\
total & Sig. (2-tailed) & \\
& N & 20 \\
\hline
\end{tabular}

Setelah diuji validitasnya, instrument yang valid diuji reliabilitasnya. Setelah dianalisis menggunkan SPSS, nilai Alpha sebesar 0,840, kemudian perolehan nilai Alpha ini dibandingkan dengan nilai $r$ tabel dengan menggunakan rumus df $=\mathrm{N}-2=20-2=18$. Nilai $\mathrm{df}=18$ pada distribusi nilai $\mathrm{r}$ tabel signifikan $5 \%$ diperoleh nilai $r$ tabel sebesar 0,444 . Berikut hasil uji reliabilitas instrumen

Tabel 3. Uji Reliabilitas

\begin{tabular}{|r|r|}
\hline Cronbach's Alpha & N of Items \\
& \\
\hline, 840 & \\
\hline
\end{tabular}

Kesimpulan dari penghitungan diatas adalah 0,840>0,444, sehingga dapat disimpulkan bahwa instrumen soal reliabel untuk digunakan sebagai alat pengambilan data dalam penelitian.

Penelitian dan pengambilan data dilaksanakan di Sekolah Dasar Islam Terpadu (SDIT) Al-Madinah Cibinong yang beralamat di Jl. Sukahati No 36 Kelurahan Karadenan, Kecamatan Cibinong, Kabupaten Bogor pada tanggal 7 Mei 2018 sampai 9 Mei 2018. Data hasil nilai diambil dari kelas 3C sebagai kelas eksperimen yang menggunakan strategi Inquiring Minds Want to Know dan kelas 3D sebagai kelas kontrol yang menggunakan cara konvensional atau menggunakan ceramah.

\section{HASIL DAN DISKUSI}

Sebelum data diolah, perlu diuji normalitas dan homogenitas terlebih dahulu untuk mengetahui apakah data terdistribusi normal dan homogeny. Penjelasan mengenai uji normalitas dan homogenitas data dapat dilihat dalam tabel berikut: 
Tabel 4. Data Output Uji Normalitas Hasil Belajar

One-Sample Kolmogorov-Smirnov Test

\begin{tabular}{|ll|l|}
\hline & & Unstandardized Residual \\
\hline $\mathrm{N}$ & & 100 \\
Normal Parameters ${ }^{\mathrm{a}, \mathrm{b}}$ & Mean & $0 \mathrm{E}-7$ \\
& Std. Deviation & 13,49323512 \\
& Absolute &, 058 \\
Most Extreme Differences & Positive &, 058 \\
& Negative &,- 049 \\
Kolmogorov-Smirnov Z & &, 583 \\
Asymp. Sig. (2-tailed) & &, 885 \\
\hline
\end{tabular}

a. Test distribution is Normal.

b. Calculated from data.

Berdasarkan hasil olah data uji normalitas pretest dan posttest baik kelas eksperimen maupun kelas kontrol menunjukkan hasil output sebesar 0,885. Hal ini bermakna bahwa 0,885 lebih besar dari 0,05. Sehingga dapat disimpulkan bahwa data pretest dan posttest kelas eksperimen dan kontrol merupakan data yang terdistribusi normal.

Tabel 5. Data Output Uji homogenitas

Test of Homogeneity of Variances

Hasil Belajar IPS

\begin{tabular}{|l|l|l|l|}
\hline $\begin{array}{c}\text { Levene } \\
\text { Statistic }\end{array}$ & df1 & df2 & Sig. \\
\hline, 079 & 3 & 96 &, 971 \\
\hline
\end{tabular}

Dari data tabel diatas, dapat diketahui bahwa hasil output uji homogenitas adalah sebesar 0.971. Hal ini berarti bahwa 0.971 lebih besar dari 0.05 yang mana hal ini menunjukkan bahwa data pretest dan posttest kelas eksperimen dan kontrol tersebut dapat dikategorikan sebagai data yang homogen.

Hasil penelitian berupa deskripsi data pretest dan posttest kelas eksperimen dan kontrol dapat dilihat dalam tabel berikut

Tabel 6. Hasil Pretest Kelas Eksperimen dan Kontrol

\begin{tabular}{|l|c|c|}
\hline \multirow{2}{*}{\multicolumn{1}{|c|}{ Komponen }} & \multicolumn{2}{c|}{ Hasil Pretest } \\
\cline { 2 - 3 } & Eksperimen & Kontrol \\
\hline Jumlah siswa & 25 & 25 \\
\hline Nilai tertinggi & 92 & 88 \\
\hline Nilai terendah & 33 & 50 \\
\hline Rata-rata & 66.28 & 67.56 \\
\hline
\end{tabular}

Berdasarkan tabel diatas, dapat disimpulkan bahwa rata-rata nilai pretest kelas eksperimen (66.28) lebih rendah dari pada kelas kontrol (67.56). Hasil posttest kelas eksperimen dan kontrol dapat dilihat dalam tabel berikut 
Tabel 7. Hasil Posttest Kelas Eksperimen dan Kontrol

\begin{tabular}{|c|c|c|}
\hline \multirow{2}{*}{ Komponen } & \multicolumn{2}{|c|}{ Hasil posttest } \\
\cline { 2 - 3 } & Eksperimen & Kontrol \\
\hline Jumlah siswa & 25 & 25 \\
\hline Nilai tertinggi & 100 & 100 \\
\hline Nilai terendah & 50 & 58 \\
\hline Rata-rata & 83.6 & 74 \\
\hline
\end{tabular}

Dari data posttest diatas diketahui bahwa kedua kelas mengalami kenaikan rata-rata, akan tetapi nilai rata-rata kelas eksperimen lebih tinggi daripada kelas kontrol. Dari data pretest dan posttest yang telah diolah menunjukkan bahwa data terdistribusi normal dan homogen. Maka langkah selanjutnya adalah uji hipotesis menggunakan parametric test yaitu Independent sampel t-Test. pengujian ini dilakukan untuk mengetahui hipotesis manakah diantara Ha (hipotesis alternatif) dan Ho (hipotesis nol) yang akan ditolak dan diterima. Pengujian hipotesis dalam penelitian ini adalah dengan membandingkan t tabel dan t hitung.

Tabel 8. Independent Samples Test

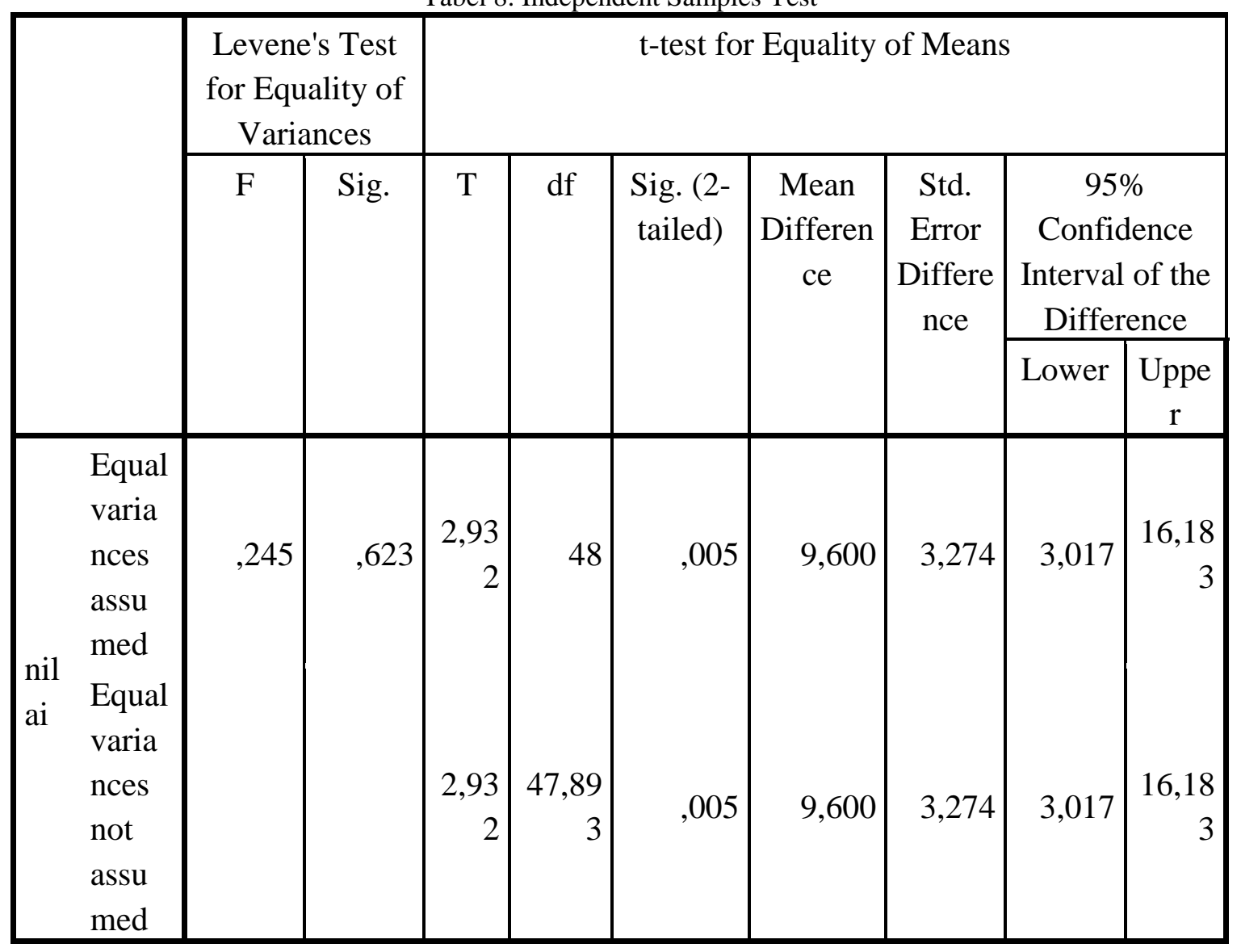

Sebelum menganalisa tabel diatas, perlu menentukan derajat bebas (df) untuk mengetahui nilai t pada taraf signifikansi $5 \%$ dan $1 \%$. Dari data penelitian $\mathrm{df}=\left(\mathrm{N}_{1}+\mathrm{N}_{2}\right)-2$ $=(25+25)-2=50-2=48$, maka df $=48$. Dalam Anas Sudijono, taraf signifikansi df 48 
untuk 5\% adalah 2.02 dan $1 \%$ adalah 2.69. Dapat diketahui melalui tabel diatas bahwa t hitung adalah sebesar 2.932 .

Hasil t hitung yang didapatkan dalam uji Independent sample t-Test adalah 2.932. Sedangkan t tabel untuk taraf signifikansi 5\% adalah 2.02 dan $1 \%$ adalah 2.69. Sehingga dapat diketahui bahwa thitung lebih besar daripada t tabel yaitu $2.02<2.932>2.69$. Jadi dapat disimpulkan bahwa Ha diterima dan $\mathrm{Ho}$ ditolak.

\section{KESIMPULAN}

Pembelajaran Ilmu Pengetahuan Sosial (IPS) menggunakan strategi Inquiring Minds Want to Know memberikan pengaruh terhadap hasil belajar siswa. Hal ini dapat dibuktikan dengan hasil uji t (Independent Sample t-Test) dengan membandingkan nilai t tabel dengan t hitung yang menyatakan bahwa setelah dilakukan analisis penghitungan menggunakan spss 20. Nilai t hitung didapatkan sebesar 2.932 dan nilai t tabel pada signifikansi $5 \%$ adalah sebesar 2.02 dan 2.69 pada taraf signifikansi $1 \%$, sehingga dapat di interpretasikan nilai $t$ hitung lebih besar dari nilai $t$ tabel yaitu $2.02<2.932>2.69$ yang mana hal ini menunjukkan bahwa Ha diterima dan H0 ditolak. Dengan diterimanya Ha dan Ditolaknya $\mathrm{H}$, dapat disimpulkan bahwa penerapan strategi Inquiring Minds Want to Know berpengaruh terhadap hasil belajar IPS siswa kelas 3 SDIT Al-Madinah Cibinong.

\section{DAFTAR PUSTAKA}

Majid, A. (2014). Pembelajaran Tematik Terpadu. Bandung: PT. Remaja Rosdakarya. Silbermen, M. L. (2009). Active Learning. Yogyakarta: Pustaka Insan Madani.

Sugiyono. (2016). Metode Penelitian Pendidikan. Depok: Penerbit Alfabeta.

Sukmadinata, N. S. (2011). Metode Penelitian Pendidikan. Bandung: PT. Remaja Rosdakarya.

Sudijono, Anas, Pengantar Statistik Pendidikan, Jakarta: PT. Raja Grafindo Persada, 2015. 